\title{
Tolerância de Novos Genótipos de Cana-de-Açúcar a Herbicidas ${ }^{1}$
}

\author{
Tolerance of New Sugarcane Genotypes to Herbicides
}

\author{
GALON, L. ${ }^{2}$, FERREIRA, F.A. ${ }^{3}$, FERREIRA, E.A. ${ }^{4}$, SILVA, A.A. ${ }^{3}$, CONCENÇO, G. ${ }^{2}$, SILVA, A.F. ${ }^{2}$, \\ REIS, M.R. ${ }^{2}$, ASPIAZÜ, I. ${ }^{2}$, FIALHO, C.M.T. ${ }^{5}$, BARBOSA, M.H.P. ${ }^{3}$ e TIRONI, S.P. ${ }^{5}$
}

\begin{abstract}
RESUMO - Avaliaram-se neste trabalho os efeitos dos herbicidas ametryn, trifloxysulfuronsodium e a mistura (ametryn + trifloxysulfuron-sodium) sobre os componentes da produtividade de dez genótipos de cana-de-açúcar. O experimento foi realizado em um Argissolo Vermelho-Amarelo em blocos casualizados, com parcelas subdivididas. Nas parcelas alocaramse os herbicidas: ametryn (2.000 $\left.\mathrm{g} \mathrm{ha}^{-1}\right)$, tryfloxysulfuron-sodium $\left(22,5 \mathrm{~g} \mathrm{ha}^{-1}\right)$ e a mistura formulada comercialmente, ametryn + trifloxysulfuron-sodium $\left(1.463+37,0 \mathrm{~g} \mathrm{ha}^{-1}\right)$, e uma testemunha sem aplicação de herbicidas (capinada). Os herbicidas foram aplicados em pósemergência inicial da cultura. Nas subparcelas, foram plantados os genótipos de cana-deaçúcar: RB72454, RB835486, RB855113, RB855156, RB867515, RB925211, RB925345, RB937570, RB947520 e SP80-1816. Aos 14, 45 e 60 dias após aplicação dos herbicidas (DAT) avaliou-se, por meio de notas, a intoxicação dos genótipos de cana-de-açúcar pelos herbicidas. Aos 14 e 45 DAT, determinaram-se a área foliar e a massa da matéria seca da parte aérea. A altura das plantas foi avaliada aos 14 e 360 DAT, e a produtividade de colmos foi determinada por ocasião da colheita, aos 430 dias após o plantio. O genótipo RB855156 foi o mais sensivel aos produtos aplicados, e os genótipos RB925345, RB947520 e SP80-1816, os mais tolerantes. Em todos os casos de intoxicação, verificou-se completa recuperação da cultura até 60 DAT. Conclui-se que a seletividade da cana-de-açúcar aos herbicidas ametryn, trifloxysulfuronsodium e ametryn + trifloxysulfuron-sodium é dependente do genótipo cultivado.
\end{abstract}

Palavras-chave: Saccharum spp., seletividade de herbicidas, ametryn, trifloxysulfuron-sodium.

\begin{abstract}
The effects of the herbicides ametryn, trifloxysulfuron-sodium and the mixture (ametryn + trifloxysulfuron-sodium) on the yield components of ten sugarcane genotypes were evaluated in this study. The experiment was conducted in a Paleudultand and t was arranged in a randomized block design with split plots. The herbicides ametryn $\left(2.000 \mathrm{~g} \mathrm{ha}^{-1}\right)$, tryfloxysulfuron-sodium $\left(22,5 \mathrm{~g} \mathrm{ha}^{-1}\right)$ were allocated in the plots as well the commercial mixture ametryn + trifloxysulfuronsodium (1.463 + $\left.37 \mathrm{~g} \mathrm{ha}^{-1}\right)$ and control without herbicide application (hoed). The herbicides were applied at as initial post-emergence of the crop. The sugar cane genotypes (RB72454, RB835486, RB855113, RB855156, RB867515, RB925211, RB925345, RB937570, RB947520 and SP801816) were allocated in the subplots. At 14, 45 and 60 days aftertreatment application (DTA), sugarcane genotype intoxication by the herbicides was evaluated, using grades. At 14 and 45 DTA, plants had their leaf area and dry matter determined. Plant height was measured at 14 and 360 DTA, and stem productivity was determined by harvest time, 430 days after planting. The genotype RB855156 was the most sensitive to the applied products and the genotypes RB925345, RB947520 and SP80-1816, the most tolerant. In all cases of intoxication, a complete recovery of the crop was observed up to 60 DTA. It was concluded that selectivity of sugarcane to the herbicides ametryn, trifloxysulfuron-sodium and ametryn + trifloxysulfuron-sodium is dependent on the cultivated genotype.
\end{abstract}

Keywords: Saccharum spp., herbicide selectivity, ametryn, trifloxysulfuron-sodium.

1 Recebido para publicação em 11.11.2009 e na forma revisada em 15.6.2010.

2 Engo-Agro. ., M.Sc., Doutorando no Programa de Pós-Graduação em Fitotecnia, Dep. de Fitotecnia, Universidade Federal de Viçosa - DFT/UFV, Bolsista do CNPq-Brasil, 36570-000 Viçosa-MG, <galonleandro@ig.com.br>; ${ }^{3}$ Prof. do DFT/UFV, Bolsista em produtividade de pesquisa do CNPq; ${ }^{4}$ Engo-Agro ${ }^{-}$, D. Sc., Pós-Doutorado - DFT/UFV; ${ }^{5}$ Eng $\stackrel{0}{ }$ Agr ${ }^{\circ}$., Mestrando no DFT/UFV.

Planta Daninha, Viçosa-MG, v. 28, n. 2, p. 329-338, 2010 


\section{INTRODUÇÃO}

Nos últimos anos a cana-de-açúcar se expandiu rapidamente, tornando-se matériaprima de grande importância à economia do Brasil, que é líder mundial nas agroindústrias de açúcar e álcool (Christoffoleti et al., 2008). No entanto, a produtividade dessa cultura poderia ser ainda maior se fossem controlados com eficiência alguns fatores bióticos e abióticos que limitam a produção. Entre os fatores, a interferência exercida pelas plantas daninhas na cultura causa-lhe perdas expressivas de produtividade, de qualidade do produto colhido e redução da longevidade do canavial (Kuva et al., 2003; Negrisoli et al., 2004).

O controle de plantas daninhas nos canaviais brasileiros, cujas áreas são extensas, é feito basicamente pelo método químico, tanto em pré como em pós-emergência, por causa da praticidade, da alta eficiência e do baixo custo do controle, quando comparado aos demais métodos de controle (Christoffoleti et al., 2006; Kuva et al., 2008). Todavia, os herbicidas podem exercer efeitos diretos e indiretos sobre a cultura, ocasionando intoxicações (Das et al., 2003; Rizzardi et al., 2003), o que pode ter como consequência a redução das taxas de crescimento e desenvolvimento do canavial. Entretanto, alguns efeitos, como alteração na absorção de nutrientes e desregulação dos mecanismos de defesa da cultura a determinados fatores abióticos ou bióticos, não são perceptiveis nem amplamente considerados (Rizzardi et al., 2003), sendo relatados por poucos autores (Feng et al., 2005; Tuffi Santos, 2007).

Os efeitos de intoxicação não devem ser determinados apenas verificando os sintomas visuais, pois já são conhecidos exemplos de herbicidas que podem reduzir a produtividade das culturas sem causar efeitos visualmente detectáveis. Por sua vez, alguns herbicidas podem ocasionar injúrias acentuadas, que desaparecem com o desenvolvimento da cultura (Velini et al., 2000; Negrisoli et al., 2004). A seletividade de herbicidas à cultura da cana-de-açúcar é muito dependente das características físico-químicas e da dose do herbicida, do estádio de desenvolvimento, da suscetibilidade dos genótipos e das condições edafoclimáticas no momento da aplicação. Pesquisas realizadas por Velini et al. (2000),
Freitas et al. (2004) e Ferreira et al. (2005) demonstram distintas respostas de genótipos à aplicação de herbicidas, tendo como consequências frequentes problemas de intoxicação e, às vezes, quedas na produtividade do canavial. Vale ressaltar que as características genéticas associadas ao estádio de desenvolvimento da cana-de-açúcar são fatores preponderantes na tolerância de genótipos a herbicidas (Procópio et al., 2004).

$\mathrm{Na}$ atualidade estão registrados no Ministério da Agricultura, Pecuária e Abastecimento (MAPA) 42 ingredientes ativos e 189 marcas comerciais de herbicidas recomendados para a cultura da cana-de-açúcar (AGROFIT, 2008). Entre esses herbicidas, destacam-se o ametryn e o trifloxysulfuronsodium, aplicados isolados ou em mistura formulada.

O ametryn é um dos herbicidas mais empregados no controle de plantas daninhas na cultura da cana-de-açúcar, podendo ser aplicado em pré ou pós-emergência inicial (Rodrigues \& Almeida, 2005). Os sintomas de intoxicação causados por esse herbicida caracterizam-se por clorose seguida de necrose das folhas (Velini et al., 2000). Em aplicações em pós-emergência, os sintomas são mais acentuados nos pontos de contato da calda herbicida com as folhas (Procópio et al., 2004). Outro herbicida recomendado para controle de dicotiledôneas e ciperáceas e algumas gramíneas, em pós-emergência, nessa cultura é o trifloxysulfuron-sodium (Rodrigues \& Almeida, 2005). A intoxicação das plantas de cana-deaçúcar por esse herbicida caracteriza-se por amarelecimento inicial das folhas, redução do crescimento e morte destas em uma a três semanas após a aplicação (Oliveira Jr. et al., 2001). Ferreira et al. (2005), ao avaliarem 15 genótipos de cana-de-açúcar, verificaram tolerância diferencial à mistura formulada do ametryn + trifloxysulfuronsodium, existindo materiais com alta, média e baixa suscetibilidade a essa formulação. Esses autores observaram efeitos diferenciados dessa mistura na altura de planta, no número de folhas, na área foliar e na massa da matéria seca da parte aérea e do caule dos genótipos avaliados. Segundo Procópio et al. (2004) e Ferreira et al. (2005), o trifloxysulfuron-sodium, apesar de causar 
intoxicação diferenciada aos genótipos de cana-de-açúcar, está sendo amplamente utilizado em pós-emergência inicial, com excelente controle de várias espécies das familias Poaceae e Ciperaceae (Rawls et al., 2003). A mistura desse herbicida com o ametryn demonstrou boa eficácia no controle de plantas daninhas e também boa seletividade, com moderada intoxicação, da mistura de trifloxysulfuron-sodium + ametryn ou com MSMA em lavouras de cana-de-açúcar (Freitas et al., 2004; Ferreira et al., 2005). Outros herbicidas, como oxyfluorfen + ametryn, em trabalhos realizados por Victória Filho \& Camargo (1980) e Velini et al. (2000), não provocaram efeitos adversos sobre o crescimento (emissão de folhas e altura das plantas), perfilhamento, produtividade e qualidade da matéria-prima dos colmos de alguns genótipos.

Considerando que há diferenciação dos genótipos de cana-de-açúcar quanto à seletividade destes a herbicidas, objetivou-se com este trabalho avaliar a influência dos herbicidas trifloxysulfuron-sodium e ametryn, aplicados de forma isolada ou em mistura formulada, sobre os componentes da produtividade de dez genótipos de cana-de-açúcar.

\section{MATERIAL E MÉTODOS}

O experimento foi realizado em campo na estação experimental da Universidade Federal de Viçosa, município de Oratórios-MG, em um Argissolo Vermelho-Amarelo (Embrapa, 2006). $\mathrm{O}$ preparo da área foi realizado em sistema convencional de cultivo, com aração seguida de gradagens e sulcamento para o plantio dos colmos de cana-de-açúcar.

A correção do $\mathrm{pH}$ e a adubação foram efetuadas, antes do plantio, com base na análise de solo (Tabela 1) e nas recomendações técnicas para a cultura (CFSEMG, 1999). Anteriormente ao plantio, foram distribuídos nos sulcos de plantio $500 \mathrm{~kg} \mathrm{ha}^{-1}$ da fórmula 6-30-24. O plantio foi realizado em 27/4/2007, na densidade de 16 gemas $\mathrm{m}^{-1}$. Após a distribuição dos colmos dentro dos sulcos, eles foram picados em toletes de três a cinco gemas e cobertos com uma camada de solo de aproximadamente $5 \mathrm{~cm}$.

O delineamento experimental utilizado foi o de blocos casualizados em esquema de parcelas subdivididas, com quatro repetições. Nas parcelas foram alocados os herbicidas [ametryn - $2.000 \mathrm{~g} \mathrm{ha}^{-1}$ (Metrimex $500 \mathrm{SC}^{\circledR}$ ), trifloxysulfuron-sodium - 22,5 $\mathrm{g} \mathrm{ha}^{-1}\left(\right.$ Envoke $\left.^{\circledR}\right)$, a mistura formulada comercialmente ametryn + trifloxysulfuron-sodium - $1.463+37,0 \mathrm{~g} \mathrm{ha}^{-1}$ $\left(\right.$ Krismat $\left.^{\mathbb{}}\right)$ ] e mais uma testemunha capinada. Nas subparcelas, plantaram-se os genótipos de cana-de-açúcar: RB72454, RB835486, RB855113, RB855156, RB867515, RB925211, RB925345, RB937570, RB947520 e SP80-1816. A aplicação dos herbicidas foi realizada aos 70 dias após o plantio (em pós-emergência inicial), quando a cultura se encontrava com aproximadamente $40 \mathrm{~cm}$ de altura, com pulverizador costal de precisão pressurizado a $\mathrm{CO}_{2}$, munido com barra de $2 \mathrm{~m}$ de comprimento e, acopladas a esta, quatro pontas de pulverização da série TT 110.02 espaçadas de $0,5 \mathrm{~m}$, operando a uma pressão constante de

Tabela 1 - Análise química do solo Argissolo Vermelho-Amarelo utilizado no experimentoํㅡㄹ. Oratórios-MG, 2007

\begin{tabular}{|c|c|c|c|c|c|c|c|c|}
\hline \multirow{2}{*}{\multicolumn{2}{|c|}{ Camada amostrada }} & $\mathrm{pH}$ & $\mathrm{P}$ & $\mathrm{K}^{+}$ & $\mathrm{H}+\mathrm{Al}$ & $\mathrm{Al}^{3+}$ & $\mathrm{Ca}^{2+}$ & $\mathrm{Mg}^{2-}$ \\
\hline & & $\left(\mathrm{H}_{2} \mathrm{O}\right)$ & \multicolumn{3}{|c|}{$\left(\mathrm{mg} \mathrm{dm}^{-3}\right)$} & \multicolumn{3}{|c|}{$\left(\mathrm{cmol}_{\mathrm{c}} \mathrm{dm}^{-3}\right)$} \\
\hline & $\mathrm{cm}$ & 5,1 & 4,5 & 33 & 2,15 & 0,2 & 1,5 & 0,7 \\
\hline SB & CTC (t) & CTC (T) & $\mathrm{v}$ & $\mathrm{m}$ & MO & Argila & Areia & Silte \\
\hline \multicolumn{3}{|c|}{$\left(\mathrm{cmol}_{\mathrm{c}} \mathrm{dm}^{-3}\right)$} & \multicolumn{2}{|c|}{$(\%)$} & \multicolumn{2}{|c|}{$\left(\right.$ dag kg $\left.^{-1}\right)$} & \multicolumn{2}{|c|}{$(\%)$} \\
\hline 2,28 & 2,48 & 2,48 & 51 & 8,0 & 0,9 & 39 & 43 & 18 \\
\hline
\end{tabular}

1/ Análise realizada no Laboratório de Análise de Solos Viçosa Ltda. pH: em água, relação 1:2,5. P-K: extrator Mehlich 1. Ca-Mg e Al: extrator $\mathrm{KCl}-1 \mathrm{~mol} \mathrm{~L}^{-1} \cdot \mathrm{H}+\mathrm{Al}$ : extrator acetato de cálcio $0,5 \mathrm{~mol} \mathrm{~L}^{-1}-\mathrm{pH} 7,0$. SB: soma de bases trocáveis. CTC (t): capacidade de troca catiônica efetiva. CTC $(\mathrm{T})$ : capacidade de troca catiônica a $\mathrm{pH} 7,0$. v: saturação de bases. m: saturação de alumínio. MO: matéria orgânica $=$ C.org x 1,724 - Walkley-Black. 
$2,0 \mathrm{kgf} \mathrm{cm}^{-2}$, o que possibilitou a aplicação de um volume de calda herbicida equivalente a $150 \mathrm{~L} \mathrm{ha}^{-1}$.

Foram plantadas dez linhas de cana-deaçúcar, com $10 \mathrm{~m}$ de comprimento, espaçadas de 1,40 m, sendo cada linha constituída por um genótipo, o que representou as unidades experimentais. Sobre os genótipos, em cada parcela, aplicaram-se os herbicidas ametryn, trifloxysulfuron-sodium e a mistura deles. A intoxicação dos genótipos foi avaliada visualmente aos 14, 45 e 60 dias após a aplicação dos herbicidas (DAT), nas linhas centrais de cada parcela, utilizando-se escala percentual, em que zero e 100 corresponderam à ausência de injúria e morte total das plantas, respectivamente. Avaliaram-se dez plantas no centro de cada parcela, para determinar: área foliar, massa da matéria seca da parte aérea (aos 14 e 45 DAT) e altura de plantas (aos 14 e 360 DAT). As estimativas da produção dos genótipos foram feitas colhendo-se todas as plantas com os colmos viáveis comercialmente, que foram convertidos em $\mathrm{tha}^{-1} \mathrm{em}$ cada tratamento no momento da colheita, aos 430 dias após o plantio.

As variáveis foram transformadas em porcentagem em relação à testemunha e, posteriormente, analisadas quanto à sua homocedasticidade, sendo submetidas logo em seguida

Tabela 2 - Intoxicação (\%) da cana-de-açúcar, avaliada aos 14 dias após a aplicação dos herbicidas, em função de genótipos ou da aplicação de herbicidas isolados ou em mistura comercial

\begin{tabular}{|l|c|c|c|c|}
\hline \multirow{2}{*}{ Genótipo } & \multicolumn{4}{|c|}{ Herbicida } \\
\cline { 2 - 5 } & $\mathrm{TC}^{\underline{\underline{I}}}$ & $\mathrm{HA}$ & $\mathrm{HB}$ & $\mathrm{HC}$ \\
\hline RB72454 & $0,00 \mathrm{aC}^{-1}$ & $9,25 \mathrm{aA}$ & $5,25 \mathrm{bB}$ & $8,00 \mathrm{bA}$ \\
\hline RB835486 & $0,00 \mathrm{aB}$ & $7,75 \mathrm{bA}$ & $6,00 \mathrm{bA}$ & $6,50 \mathrm{bA}$ \\
\hline RB855113 & $0,00 \mathrm{aD}$ & $11,00 \mathrm{aA}$ & $4,50 \mathrm{bC}$ & $7,00 \mathrm{bB}$ \\
\hline RB855156 & $0,00 \mathrm{aB}$ & $9,25 \mathrm{aA}$ & $9,25 \mathrm{aA}$ & $11,00 \mathrm{aA}$ \\
\hline RB867515 & $0,00 \mathrm{aC}$ & $6,50 \mathrm{bA}$ & $4,50 \mathrm{bB}$ & $7,00 \mathrm{bA}$ \\
\hline RB925211 & $0,00 \mathrm{aC}$ & $8,00 \mathrm{bA}$ & $5,25 \mathrm{bB}$ & $9,25 \mathrm{aA}$ \\
\hline RB925345 & $0,00 \mathrm{aB}$ & $5,75 \mathrm{cA}$ & $6,75 \mathrm{bA}$ & $6,50 \mathrm{bA}$ \\
\hline RB937570 & $0,00 \mathrm{aC}$ & $7,25 \mathrm{bA}$ & $5,50 \mathrm{bB}$ & $4,25 \mathrm{cB}$ \\
\hline RB947520 & $0,00 \mathrm{aB}$ & $4,75 \mathrm{cA}$ & $5,25 \mathrm{bA}$ & $5,50 \mathrm{cA}$ \\
\hline SP80-1816 & $0,00 \mathrm{aC}$ & $10,50 \mathrm{aA}$ & $6,25 \mathrm{bB}$ & $7,75 \mathrm{bB}$ \\
\hline CV parcela (\%) & \multicolumn{5}{|c|}{18,71} \\
\hline CV subparcela (\%) & \multicolumn{5}{|c|}{27,42} \\
\hline
\end{tabular}

1/ TC: testemunha capinada; HA: ametryn $\left(2.000 \mathrm{~g} \mathrm{ha}^{-1}\right)$; HB trifloxysulfuron-sodium $\left(22,5 \mathrm{~g} \mathrm{ha}^{-1}\right) ; \mathrm{HC}$ : ametryn trifloxysulfuron-sodium $\left(1.673+37,0 \mathrm{~g} \mathrm{ha}^{-1}\right)$. ${ }^{2 /}$ Médias seguidas de mesmas letras minúsculas, na coluna, e maiúsculas, na linha, constituem grupos homogêneos, conforme Scott-Knott $(\mathrm{p} \leq 0,05)$ à análise de variância. Após atenderem às premissas propostas anteriormente, efetuouse o teste de agrupamento de médias de Scott $\&$ Knott (1974). A probabilidade de erro aplicada em todos os testes foi de $\mathrm{p} \leq 0,05$.

\section{RESULTADOS E DISCUSSÃO}

Houve interação significativa entre genótipos $\mathrm{x}$ herbicidas para todas as variáveis estudadas. Os resultados demonstraram que, para a variável intoxicação de plantas avaliada aos 14 DAT, o genótipo de cana-de-açúcar RB855156 foi o mais sensivel aos herbicidas. Todavia, os genótipos RB72454, RB855113, RB855156 e SP80-1816 foram mais sensiveis apenas ao ametryn, com valores de 9,25; 11,00; 9,25 ; e 10,50\%, respectivamente. A mistura de ametryn + trifloxysulfuron-sodium causou elevada intoxicação nos genótipos RB855156 e RB925211 (Tabela 2).

Na segunda época de avaliação (45 DAT), os sintomas de injúria foram intensos no genótipo RB947520 tratado com o ametryn ou a mistura formulada. O trifloxysulfuronsodium ocasionou injúrias aos genótipos RB72454, RB855156, RB925211, RB925345 e SP80-1816, e somente os genótipos RB925211 e RB947520 foram intoxicados pela mistura formulada de ametryn + trifloxysulfuronsodium (Tabela 3). Comparando a intoxicação

Tabela 3 - Intoxicação (\%) de cana-de-açúcar, avaliada aos 45 dias após a aplicação dos herbicidas, em função de genótipos ou da aplicação de herbicidas isolados ou em mistura comercial

\begin{tabular}{|l|c|r|r|r|}
\hline \multirow{2}{*}{ Genótipo } & \multicolumn{4}{|c|}{ Herbicida } \\
\cline { 2 - 5 } & $\mathrm{TC}^{\underline{1}}$ & $\mathrm{HA}$ & $\mathrm{HB}$ & $\mathrm{HC}$ \\
\hline RB72454 & $0,00 \mathrm{aC}^{-2}$ & $8,00 \mathrm{bA}$ & $10,50 \mathrm{aA}$ & $4,75 \mathrm{cB}$ \\
\hline RB835486 & $0,00 \mathrm{aB}$ & $7,75 \mathrm{bA}$ & $9,00 \mathrm{bA}$ & $6,00 \mathrm{cA}$ \\
\hline RB855113 & $0,00 \mathrm{aB}$ & $6,50 \mathrm{cA}$ & $8,00 \mathrm{bA}$ & $7,75 \mathrm{cA}$ \\
\hline RB855156 & $0,00 \mathrm{aC}$ & $10,25 \mathrm{bB}$ & $13,75 \mathrm{aA}$ & $9,25 \mathrm{bB}$ \\
\hline RB867515 & $0,00 \mathrm{aB}$ & $7,00 \mathrm{cA}$ & $5,50 \mathrm{bA}$ & $5,50 \mathrm{cA}$ \\
\hline RB925211 & $0,00 \mathrm{aC}$ & $5,75 \mathrm{cB}$ & $13,25 \mathrm{aA}$ & $11,75 \mathrm{aA}$ \\
\hline RB925345 & $0,00 \mathrm{aC}$ & $4,25 \mathrm{cB}$ & $12,75 \mathrm{aA}$ & $10,50 \mathrm{bA}$ \\
\hline RB937570 & $0,00 \mathrm{aC}$ & $8,75 \mathrm{bA}$ & $7,50 \mathrm{bA}$ & $4,50 \mathrm{cB}$ \\
\hline RB947520 & $0,00 \mathrm{aC}$ & $15,00 \mathrm{aA}$ & $11,25 \mathrm{aB}$ & $13,50 \mathrm{aA}$ \\
\hline SP80-1816 & $0,00 \mathrm{aD}$ & $9,25 \mathrm{bB}$ & $12,75 \mathrm{aA}$ & $6,25 \mathrm{cC}$ \\
\hline CV parcela (\%) & \multicolumn{5}{|c|}{30,62} \\
\hline CV subparcela (\%) & \multicolumn{5}{|c|}{31,16} \\
\hline
\end{tabular}

1/ TC: testemunha capinada; HA: ametryn $\left(2.000 \mathrm{~g} \mathrm{ha}^{-1}\right)$; HB: trifloxysulfuron-sodium $\left(22,5 \mathrm{~g} \mathrm{ha}^{-1}\right)$; $\mathrm{HC}$ : ametryn + trifloxysulfuron-sodium $\left(1.673+37,0 \mathrm{~g} \mathrm{ha}^{-1}\right)$. ${ }^{2 /}$ Médias seguidas de mesmas letras minúsculas, na coluna, e maiúsculas, na linha, constituem grupos homogêneos, conforme Scott-Knott $(p \leq 0,05)$ 
causada pelo ametryn aos 14 e 45 DAT, observou-se que os genótipos R925345 e RB937570 apresentaram recuperação da parte aérea. Os genótipos RB855113 e SP80-1816 aos 14 DAT e o RB94750 aos 45 DAT foram os mais afetados pelo ametryn (Tabelas 2 e 3 ). O herbicida trifloxysulfuron-sodium proporcionou maior intoxicação ao RB855156 nas duas avaliações, situando-se os demais genótipos com efeitos intermediários ou baixos. A mistura formulada (ametryn + trifloxysulfuron-sodium) ocasionou a menor e a maior intoxicação aos genótipos RB937570 e RB925211, respectivamente, ao comparar estes aos demais aos 14 e 45 DAT. Aos 60 DAT houve boa recuperação dos genótipos, ou seja, baixos níveis de intoxicação pelos herbicidas, com valores médios de intoxicação de 5,50 (RB835486), 7,75 (RB72454) e 7,75\% (RB947520) para ametryn, trifloxysulfuron-sodium e ametryn + trifloxysulfuron-sodium, respectivamente, estando todos no mesmo agrupamento pelo critério de Scott-Knott (Tabela 4). Segundo Velini et al. (1993), o índice considerado tolerado pela cultura sem que ocorra redução na produtividade de colmos é $27 \%$, ficando evidente que a cultura recuperou-se dos efeitos dos herbicidas.

Ressalta-se que os genótipos menos afetados nas três épocas de avaliação demonstraram seletividade intermediária ou alta para os herbicidas. A tolerância diferencial de genótipos a herbicidas foi demonstrada por vários pesquisadores, ao utilizarem diferentes herbicidas e genótipos de cana-de-açúcar (Velini et al., 2000; Azania et al., 2001, 2005b, 2006; Ferreira et al., 2005). Resultados apresentados por Freitas et al. (2004) também mostraram baixos índices de intoxicação do cultivar RB72454 quando tratado com a mistura ametryn + trifloxysulfuron-sodium, o que corrobora o verificado neste trabalho.

A porcentagem de área foliar da cana-deaçúcar foi influenciada pelos herbicidas em relação à testemunha capinada (sem aplicação) aos 14 e 45 DAT (Tabelas 5 e 6). Na primeira avaliação, os genótipos RB72454, RB835486 e RB855113 foram menos tolerantes aos herbicidas ametryn e trifloxysulfuronsodium. O primeiro herbicida causou redução da área foliar de 40,66, 39,86 e 62,71\%, nos respectivos genótipos. $\mathrm{O}$ segundo herbicida diminuiu a área foliar em 46,08, 46,46 e
Tabela 4 - Intoxicação (\%) de cana-de-açúcar, avaliada aos 60 dias após a aplicação dos herbicidas, em função de genótipos ou da aplicação de herbicidas isolados ou em mistura comercial

\begin{tabular}{|l|c|c|c|c|}
\hline \multirow{2}{*}{ Genótipo } & \multicolumn{4}{|c|}{ Herbicida } \\
\cline { 2 - 5 } & $\mathrm{TC}^{1 /}$ & $\mathrm{HA}$ & $\mathrm{HB}$ & $\mathrm{HC}$ \\
\hline RB72454 & $0,00 \mathrm{aC}^{2}$ & $3,00 \mathrm{aB}$ & $7,75 \mathrm{aA}$ & $3,00 \mathrm{bB}$ \\
\hline RB835486 & $0,00 \mathrm{aB}$ & $5,50 \mathrm{aA}$ & $4,75 \mathrm{aA}$ & $4,50 \mathrm{bA}$ \\
\hline RB855113 & $0,00 \mathrm{aB}$ & $4,00 \mathrm{aA}$ & $5,50 \mathrm{aA}$ & $4,75 \mathrm{bA}$ \\
\hline RB855156 & $0,00 \mathrm{aC}$ & $3,00 \mathrm{aB}$ & $6,75 \mathrm{aA}$ & $6,50 \mathrm{aA}$ \\
\hline RB867515 & $0,00 \mathrm{aB}$ & $3,00 \mathrm{aA}$ & $5,25 \mathrm{aA}$ & $3,75 \mathrm{bA}$ \\
\hline RB925211 & $0,00 \mathrm{aC}$ & $3,75 \mathrm{aB}$ & $5,75 \mathrm{aA}$ & $7,00 \mathrm{aA}$ \\
\hline RB925345 & $0,00 \mathrm{aC}$ & $3,75 \mathrm{aB}$ & $6,25 \mathrm{aA}$ & $6,25 \mathrm{aA}$ \\
\hline RB937570 & $0,00 \mathrm{aB}$ & $4,00 \mathrm{aA}$ & $4,00 \mathrm{aA}$ & $3,00 \mathrm{bA}$ \\
\hline RB947520 & $0,00 \mathrm{aC}$ & $5,00 \mathrm{aB}$ & $5,75 \mathrm{aB}$ & $7,75 \mathrm{aA}$ \\
\hline SP80-1816 & $0,00 \mathrm{aB}$ & $4,25 \mathrm{aA}$ & $3,75 \mathrm{aA}$ & $4,25 \mathrm{bA}$ \\
\hline CV parcela (\%) & \multicolumn{5}{|c|}{45,29} \\
\hline CV subparcela (\%) & \multicolumn{5}{|c|}{43,58} \\
\hline
\end{tabular}

1/ TC: testemunha capinada; HA: ametryn $\left(2.000 \mathrm{~g} \mathrm{ha}^{-1}\right)$; HB trifloxysulfuron-sodium $\left(22,5 \mathrm{~g} \mathrm{ha}^{-1}\right)$; $\mathrm{HC}$ : ametryn + trifloxysulfuron-sodium $\left(1.673+37,0 \mathrm{~g} \mathrm{ha}^{-1}\right) .2$ Médias seguidas de mesmas letras minúsculas, na coluna, e maiúsculas, na linha, constituem grupos homogêneos, conforme Scott-Knott $(\mathrm{p} \leq 0,05)$

$33,12 \%$, respectivamente, ao se comparar com a testemunha sem aplicação. No entanto, esses mesmos genótipos não foram influenciados pela mistura formulada, equivalendo-se à testemunha. Os genótipos RB855156 e RB867515 apresentaram a menor área foliar sob efeito do ametryn, porém não foram afetados pelo trifloxysulfuron-sodium e pela mistura herbicida, quando comparados ao tratamento testemunha.

Os resultados demonstraram que, para a variável área foliar, os genótipos RB925211, RB947520 e SP80-1816, aos 14 DAT, foram tolerantes ao ametryn, o que não ocorreu para os genótipos RB925345 e RB937570, afetados por esse herbicida (Tabela 5). O trifloxysulfuronsodium apresentou comportamento semelhante ao da testemunha em relação aos genótipos RB925345, RB937570 e SP80-1816. Esse herbicida provocou redução da área foliar dos genótipos RB925211 e RB947520 em relação à testemunha capinada. A mistura formulada não afetou os genótipos RB925211 e RB947520. O ametryn proporcionou reduções na área foliar de 62,71 e 60,26\% dos genótipos RB835486 e RB937570; o trifloxysulfuronsodium, de 46,08 e 45,15\% em RB835486 e RB947520; e a mistura formulada, de 39,75 e 35,69\% em RB925345 e RB937570, respectivamente.

Planta Daninha, Viçosa-MG, v. 28, n. 2, p. 329-338, 2010 
A avaliação de área foliar efetuada aos 45 DAT demonstrou recuperação total dos genótipos RB72454, RB835486, RB855113, RB925211, RB937570 e RB947520, que, nessa época, não apresentavam sintomas de intoxicação, em comparação com a testemunha (Tabela 6). Nesta última avaliação, constataram-se severas injúrias provocadas pelos três herbicidas sobre o genótipo SP80-1816, com redução em torno de 64,11, 45,92 e 60,42\% para ametryn, trifloxysulfuron-sodium e ametryn + trifloxysulfuron-sodium, respectivamente. O trifloxysulfuron-sodium proporcionou redução da área foliar somente para o genótipo RB925345. Os genótipos RB855156 e RB867515 demonstraram ser tolerantes ao ametryn, com nenhuma redução da área foliar; contudo, para os demais herbicidas, esses genótipos tiveram intoxicação da parte aérea de 8 a $40,2 \%$.

Ao se compararem as duas épocas de avaliação, não se observou injúria na área foliar dos genótipos RB855156 e RB925211 pelo uso de ametryn, porém os demais genótipos situaram-se com média ou baixa tolerância (Tabelas 5 e 6). O uso do trifloxysulfuronsodium também não afetou os genótipos RB867515, RB925345 e RB937570. Os demais genótipos foram todos influenciados pelo uso do herbicida. Os genótipos RB72454 e SP80-1816 foram os que sofreram menor e maior danos pela mistura formulada nas avaliações de 14 e 45 DAT, enquanto os demais genótipos mostraram tolerância intermediária ao ametryn + triloxysulfuron-sodium.

Ferreira et al. (2005), ao trabalharem com a mistura de ametryn + trifloxysulfuronsodium em várias doses e genótipos de canade-açúcar, também constataram haver diferenciação dos genótipos quanto ao uso do herbicida, ou seja, ocorre maior ou menor efeito sobre o desenvolvimento da área foliar em função da dose do produto e também de acordo com o genótipo de cana-de-açúcar. Velini et al. (2000), ao testarem os herbicidas oxyfluorfen e ametryn isolados e em mistura, constataram diferentes niveis de danos na área foliar de dez genótipos. Esses autores observaram ainda que a modalidade de aplicação do herbicida em pré ou em pós-emergência também altera os danos provocados sobre a área foliar da cultura em determinada situação, elevando-os e, em outros casos, diminuindo-os. Destaca-se que a área foliar tem importância crucial para o crescimento, desenvolvimento e produtividade das culturas. Assim, quanto maior a área foliar, maior será a capacidade das plantas de capturar luz, ocorrendo aumento na taxa fotossintética e, consequentemente, aumento na produtividade da cana-de-açúcar (Inman-Bamber, 1994).

Tabela 5 - Área foliar (\%) de cana-de-açúcar, avaliada aos 14 dias após a aplicação dos herbicidas, em função de genótipos ou da aplicação de herbicidas isolados ou em mistura comercial

\begin{tabular}{|l|l|r|r|r|}
\hline \multirow{2}{*}{ Genótipo } & \multicolumn{4}{|c|}{ Herbicida } \\
\cline { 2 - 5 } & \multicolumn{1}{|c|}{$\mathrm{TC}^{\underline{-}}$} & \multicolumn{1}{c|}{ HA } & \multicolumn{1}{c|}{$\mathrm{HB}$} & \multicolumn{1}{c|}{ HC } \\
\hline RB72454 & $100,00 \mathrm{aA}^{2}$ & $59,34 \mathrm{bB}$ & $60,14 \mathrm{bB}$ & $99,18 \mathrm{aA}$ \\
\hline RB835486 & $100,00 \mathrm{aA}$ & $37,29 \mathrm{cC}$ & $53,92 \mathrm{bB}$ & $92,75 \mathrm{aA}$ \\
\hline RB855113 & $100,00 \mathrm{aA}$ & $53,54 \mathrm{bB}$ & $66,88 \mathrm{bB}$ & $100,00 \mathrm{aA}$ \\
\hline RB855156 & $100,00 \mathrm{aA}$ & $82,89 \mathrm{aA}$ & $100,00 \mathrm{aA}$ & $100,00 \mathrm{aA}$ \\
\hline RB867515 & $100,00 \mathrm{aA}$ & $63,65 \mathrm{bB}$ & $89,67 \mathrm{aA}$ & $89,82 \mathrm{aA}$ \\
\hline RB925211 & $100,00 \mathrm{aA}$ & $96,31 \mathrm{aA}$ & $72,24 \mathrm{bB}$ & $100,00 \mathrm{aA}$ \\
\hline RB925345 & $100,00 \mathrm{aA}$ & $69,25 \mathrm{bB}$ & $98,55 \mathrm{aA}$ & $60,25 \mathrm{bB}$ \\
\hline RB937570 & $100,00 \mathrm{aA}$ & $39,74 \mathrm{cC}$ & $100,00 \mathrm{aA}$ & $64,31 \mathrm{bB}$ \\
\hline RB947520 & $100,00 \mathrm{aA}$ & $93,61 \mathrm{aA}$ & $54,85 \mathrm{bB}$ & $100,00 \mathrm{aA}$ \\
\hline SP80-1816 & $100,00 \mathrm{aA}$ & $100,00 \mathrm{aA}$ & $94,37 \mathrm{aA}$ & $65,37 \mathrm{bB}$ \\
\hline CV parcela (\%) & \multicolumn{5}{|c|}{10,32} \\
\hline CV subparcela (\%) & \multicolumn{5}{|c|}{14,07} \\
\hline
\end{tabular}

1/ TC: testemunha capinada; HA: ametryn $\left(2.000 \mathrm{~g} \mathrm{ha}^{-1}\right)$; HB: trifloxysulfuron-sodium $\left(22,5 \mathrm{~g} \mathrm{ha}^{-1}\right)$; $\mathrm{HC}$ : ametryn + trifloxysulfuron-sodium $\left(1.673+37,0 \mathrm{~g} \mathrm{ha}^{-1}\right) .{ }^{2 /}$ Médias seguidas de mesmas letras minúsculas, na coluna, e maiúsculas, na linha, constituem grupos homogêneos, conforme Scott-Knott $(p \leq 0,05)$

Tabela 6 - Área foliar (\%) de cana-de-açúcar, avaliada aos 45 dias após a aplicação dos herbicidas, em função de genótipos ou da aplicação de herbicidas isolados ou em mistura comercial

\begin{tabular}{|l|c|c|c|c|}
\hline \multirow{2}{*}{ Genótipo } & \multicolumn{4}{|c|}{ Herbicida } \\
\cline { 2 - 5 } & $\mathrm{TC}^{1 /}$ & $\mathrm{HA}$ & $\mathrm{HB}$ & $\mathrm{HC}$ \\
\hline RB72454 & $100,00 \mathrm{aA}^{\frac{2}{2}}$ & $100,00 \mathrm{aA}$ & $100,00 \mathrm{aA}$ & $97,46 \mathrm{aA}$ \\
\hline RB835486 & $100,00 \mathrm{aA}$ & $83,14 \mathrm{aA}$ & $98,58 \mathrm{aA}$ & $84,95 \mathrm{bA}$ \\
\hline RB855113 & $100,00 \mathrm{aA}$ & $75,26 \mathrm{aA}$ & $87,05 \mathrm{aA}$ & $77,37 \mathrm{bA}$ \\
\hline RB855156 & $100,00 \mathrm{aA}$ & $100,00 \mathrm{aA}$ & $61,68 \mathrm{bB}$ & $64,86 \mathrm{cB}$ \\
\hline RB867515 & $100,00 \mathrm{aA}$ & $100,00 \mathrm{aA}$ & $92,71 \mathrm{aA}$ & $59,80 \mathrm{cB}$ \\
\hline RB925211 & $100,00 \mathrm{aA}$ & $95,83 \mathrm{aA}$ & $93,60 \mathrm{aA}$ & $77,84 \mathrm{bA}$ \\
\hline RB925345 & $100,00 \mathrm{aA}$ & $95,01 \mathrm{aA}$ & $79,94 \mathrm{aB}$ & $100,00 \mathrm{aA}$ \\
\hline RB937570 & $100,00 \mathrm{aA}$ & $91,88 \mathrm{aA}$ & $89,94 \mathrm{aA}$ & $86,17 \mathrm{bA}$ \\
\hline RB947520 & $100,00 \mathrm{aA}$ & $82,89 \mathrm{aA}$ & $84,97 \mathrm{aA}$ & $91,16 \mathrm{bA}$ \\
\hline SP80-1816 & $100,00 \mathrm{aA}$ & $35,89 \mathrm{bB}$ & $54,08 \mathrm{bB}$ & $39,58 \mathrm{cB}$ \\
\hline CV parcela (\%) & \multicolumn{5}{|c|}{20,30} \\
\hline CV subparcela (\%) & \multicolumn{5}{|c|}{20,25} \\
\hline
\end{tabular}

1/ TC: testemunha capinada; HA: ametryn $\left(2.000 \mathrm{~g} \mathrm{ha}^{-1}\right)$; HB: trifloxysulfuron-sodium $\left(22,5 \mathrm{~g} \mathrm{ha}^{-1}\right)$; $\mathrm{HC}$ : ametryn + trifloxysulfuron-sodium $\left(1.673+37,0 \mathrm{~g} \mathrm{ha}^{-1}\right)$. ${ }^{2}$ Médias seguidas de mesmas letras minúsculas, na coluna, e maiúsculas, na linha, constituem grupos homogêneos, conforme Scott-Knott $(p \leq 0,05)$. 
Os genótipos RB855156 e RB925345 apresentaram maior acúmulo de massa da matéria seca da parte aérea (MSPA) quando comparados aos demais para os três herbicidas testados aos 14 DAT; RB835486, RB855113, RB937570 e RB947520 foram os que apresentaram a menor MSPA tanto quando comparados entre eles quanto com os herbicidas ametryn, trifloxysulfuron-sodium e ametryn + trifloxysulfuron-sodium (Tabela 7). Para os genótipos RB72454, RB867515, RB925211 e SP80-1816, o tratamento com ametryn causou menor MSPA, em comparação com a testemunha capinada e com os demais genótipos. No entanto, estes mesmos genótipos não foram afetados pelo trifloxysulfuron-sodium e pela mistura herbicida, exceto RB867515 e RB925211.

Os resultados demonstram para a MSPA, aos 45 DAT, que todos os herbicidas testados não ocasionaram efeito sobre os genótipos RB724554, RB855113, RB855156, RB867515 e RB947520, equivalendo-se à testemunha capinada, e que estes genótipos foram os melhores se comparados aos demais (Tabela 8). Os demais genótipos foram influenciados pela aplicação dos herbicidas, apresentando redução da MSPA, em comparação com o tratamento sem herbicida e também entre genótipos.

No que se refere ao efeito dos herbicidas sobre a MSPA dos genótipos de cana-de-açúcar aos 14 e 45 DAT, observa-se que o RB835486 e o SP80-1816 mantiveram a menor produção nas duas épocas avaliadas, ficando evidente que até os 45 DAT eles não se recuperaram dos efeitos da intoxicação (Tabelas 7 e 8). No entanto, os demais genótipos, apesar de terem apresentado redução da MSPA na primeira avaliação, com o passar do tempo, recuperaram-se das injúrias ocasionadas pelos herbicidas aos 45 DAT. Ressalta-se também que alguns genótipos mantiveram dos 14 até os 45 DAT a mesma produção da MSPA em relação à testemunha capinada. Assim, esses resultados - alternados para determinado genótipo ou constantes para outros - demonstram haver seletividade diferencial quando submetidos à aplicação de herbicidas.

Ao pesquisarem 15 genótipos de cana-deaçúcar submetidos à aplicação de doses de ametryn + trifloxysulfuron-sodium, Ferreira et al. (2005) constataram diferenças em relação à produção de MSPA. Avaliando ametryn, trifloxysulfuron-sodium, ametryn + trifloxysulfuron-sodium e 2,4-D, Reis et al. (2008) observaram que a mistura formulada foi a que menos alterou a produção de MSPA aos 60 DAT para o genótipo RB867515. Desse modo, fica evidente que há diferenciação na produção da MSPA em função do genótipo de cana-de-açúcar e do herbicida utilizado.

Tabela 7 - Massa da matéria seca da parte aérea (\%) de cana-deaçúcar, avaliada aos 14 dias após a aplicação dos herbicidas, em função de genótipos ou da aplicação de herbicidas isolados ou em mistura comercial

\begin{tabular}{|l|l|c|r|r|}
\hline \multirow{2}{*}{ Genótipo } & \multicolumn{4}{|c|}{ Herbicida } \\
\cline { 2 - 5 } & $\mathrm{TC}^{\underline{1}}$ & $\mathrm{HA}$ & $\mathrm{HB}$ & $\mathrm{HC}$ \\
\hline RB72454 & $100,00 \mathrm{aA}^{\frac{2}{}}$ & $52,12 \mathrm{bB}$ & $92,68 \mathrm{aA}$ & $50,43 \mathrm{cB}$ \\
\hline RB835486 & $100,00 \mathrm{aA}$ & $33,18 \mathrm{cD}$ & $47,79 \mathrm{dC}$ & $68,99 \mathrm{bB}$ \\
\hline RB855113 & $100,00 \mathrm{aA}$ & $57,60 \mathrm{bC}$ & $77,47 \mathrm{bB}$ & $49,48 \mathrm{cC}$ \\
\hline RB855156 & $100,00 \mathrm{aA}$ & $91,84 \mathrm{aA}$ & $100,00 \mathrm{aA}$ & $100,00 \mathrm{aA}$ \\
\hline RB867515 & $100,00 \mathrm{aA}$ & $32,41 \mathrm{cC}$ & $50,08 \mathrm{~dB}$ & $93,68 \mathrm{aA}$ \\
\hline RB925211 & $100,00 \mathrm{aA}$ & $67,25 \mathrm{bB}$ & $40,52 \mathrm{dC}$ & $100,00 \mathrm{aA}$ \\
\hline RB925345 & $100,00 \mathrm{aA}$ & $90,94 \mathrm{aA}$ & $88,24 \mathrm{aA}$ & $96,69 \mathrm{aA}$ \\
\hline RB937570 & $100,00 \mathrm{aA}$ & $55,08 \mathrm{bB}$ & $64,70 \mathrm{cB}$ & $72,10 \mathrm{bB}$ \\
\hline RB947520 & $100,00 \mathrm{aA}$ & $35,17 \mathrm{cD}$ & $50,63 \mathrm{dC}$ & $69,30 \mathrm{bB}$ \\
\hline SP80-1816 & $100,00 \mathrm{aA}$ & $60,52 \mathrm{bB}$ & $94,31 \mathrm{aA}$ & $100,00 \mathrm{aA}$ \\
\hline CV parcela (\%) & & \multicolumn{5}{|c}{12,55} \\
\hline CV subparcela (\%) & \multicolumn{5}{|c|}{12,45} \\
\hline
\end{tabular}

1/ TC: testemunha capinada; HA: ametryn $\left(2.000 \mathrm{~g} \mathrm{ha}^{-1}\right)$; HB: trifloxysulfuron-sodium $\left(22,5 \mathrm{~g} \mathrm{ha}^{-1}\right)$; $\mathrm{HC}$ : ametryn + trifloxysulfuron-sodium $\left(1.673+37,0 \mathrm{~g} \mathrm{ha}^{-1}\right)$. ${ }^{2 /}$ Médias seguidas de mesmas letras minúsculas, na coluna, e maiúsculas, na linha, constituem grupos homogêneos, conforme Scott-Knott $(p \leq 0,05)$.

Tabela 8 - Massa da matéria seca da parte aérea (\%) de cana-deaçúcar, avaliada aos 45 dias após a aplicação dos herbicidas, em função de genótipos ou da aplicação de herbicidas isolados ou em mistura comercial

\begin{tabular}{|l|c|c|c|c|}
\hline \multirow{2}{*}{ Genótipo } & \multicolumn{4}{|c|}{ Herbicida } \\
\cline { 2 - 5 } & $\mathrm{TC}^{1 /}$ & $\mathrm{HA}$ & $\mathrm{HB}$ & $\mathrm{HC}$ \\
\hline RB72454 & $100,00 \mathrm{aA}^{\frac{2}{2}}$ & $100,00 \mathrm{aA}$ & $100,00 \mathrm{aA}$ & $84,61 \mathrm{bA}$ \\
\hline RB835486 & $100,00 \mathrm{aA}$ & $77,94 \mathrm{bB}$ & $42,21 \mathrm{cC}$ & $87,79 \mathrm{bB}$ \\
\hline RB855113 & $100,00 \mathrm{aA}$ & $92,39 \mathrm{aA}$ & $96,07 \mathrm{aA}$ & $87,10 \mathrm{bA}$ \\
\hline RB855156 & $100,00 \mathrm{aA}$ & $100,00 \mathrm{aA}$ & $91,12 \mathrm{aA}$ & $97,99 \mathrm{aA}$ \\
\hline RB867515 & $100,00 \mathrm{aA}$ & $91,49 \mathrm{aA}$ & $90,67 \mathrm{aA}$ & $88,70 \mathrm{bA}$ \\
\hline RB925211 & $100,00 \mathrm{aA}$ & $93,15 \mathrm{aA}$ & $43,84 \mathrm{cB}$ & $96,82 \mathrm{aA}$ \\
\hline RB925345 & $100,00 \mathrm{aA}$ & $74,65 \mathrm{bB}$ & $38,41 \mathrm{cC}$ & $80,40 \mathrm{bB}$ \\
\hline RB937570 & $100,00 \mathrm{aA}$ & $70,18 \mathrm{bB}$ & $56,51 \mathrm{bB}$ & $97,68 \mathrm{aA}$ \\
\hline RB947520 & $100,00 \mathrm{aA}$ & $96,95 \mathrm{aA}$ & $100,00 \mathrm{aA}$ & $100,00 \mathrm{aA}$ \\
\hline SP80-1816 & $100,00 \mathrm{aA}$ & $65,64 \mathrm{bB}$ & $64,71 \mathrm{bB}$ & $69,81 \mathrm{bB}$ \\
\hline CV parcela (\%) & \multicolumn{5}{|c|}{12,26} \\
\hline CV subparcela (\%) & \multicolumn{5}{|c|}{13,10} \\
\hline
\end{tabular}

1/ TC: testemunha capinada; HA: ametryn $\left(2.000 \mathrm{~g} \mathrm{ha}^{-1}\right)$; HB: trifloxysulfuron-sodium $\left(22,5 \mathrm{~g} \mathrm{ha}^{-1}\right)$; $\mathrm{HC}$ : ametryn + trifloxysulfuron-sodium $\left(1.673+37,0 \mathrm{~g} \mathrm{ha}^{-1}\right) .{ }^{2 /}$ Médias seguidas de mesmas letras minúsculas, na coluna, e maiúsculas, na linha, constituem grupos homogêneos, conforme Scott-Knott $(p \leq 0,05)$. 
Os resultados demonstram, pela avaliação da altura de plantas, aos 14 DAT, que os três herbicidas testados não ocasionaram paralisação do crescimento da cultura para o genótipo RB855156; este não diferiu do tratamento sem herbicida (Tabela 9). O genótipo SP80-1816 foi menos influenciado pelo uso do ametryn e ametryn + trifloxysulfuron-sodium, e o RB855113 foi menos intoxicado quando tratado com trifloxysulfuron-sodium e a mistura formulada. Esta mistura proporcionou maior seletividade aos genótipos RB925211 e RB937570. Os demais genótipos situaram-se em patamares inferiores aos da testemunha capinada, com paralisação do crescimento de 11,99 até $39,44 \%$ ao se aplicarem os herbicidas testados.

Antes da colheita da cultura, aos 360 DAT, observou-se que os genótipos RB867515 e SP80-1816 mostraram maior altura de plantas se comparados à da testemunha capinada e dos demais genótipos, em todos os herbicidas avaliados (Tabela 10). Os resultados demonstram que os genótipos RB72454, RB835486 e RB855156 não apresentaram diferença em relação à testemunha quando foram tratados com ametryn. Resultados semelhantes foram observados para o genótipo RB937570 tratado com trifloxysulfuron-sodium e com a mistura ametryn + trifloxysulfuron-sodium. Salientase que o genótipo RB925345, nas avaliações da altura de plantas efetuadas aos 14 e 360 DAT, diferenciou-se dos demais, porém os resultados foram semelhantes entre os tratamentos com herbicidas, quando comparados com os das testemunhas (Tabelas 9 e 10).

Vários pesquisadores, ao estudarem a influência de herbicidas sobre a altura de plantas de cana-de-açúcar, constataram algum tipo de dano sobre a cultura. Reis et al. (2008) relataram que a aplicação de ametryn provocou incremento da altura de plantas do genótipo RB867515, por ser uma triazina que pode estimular o crescimento das plantas dessa cultura. No entanto, esses autores relatam que o 2,4-D, que é uma auxina, provocou paralisação do crescimento em altura de plantas nas avaliações efetuadas aos 30 e 45 DAT. Ferreira et al. (2005) demonstraram que para o genótipo RB855113 houve tendência de paralisação do crescimento das plantas quando estas foram tratadas com doses maiores de
Tabela 9 - Altura (\%) de plantas de cana-de-açúcar, avaliada aos 14 dias após a aplicação dos herbicidas, em função de genótipos ou da aplicação de herbicidas isolados ou em mistura comercial

\begin{tabular}{|l|c|c|c|c|}
\hline \multirow{2}{*}{ Genótipo } & \multicolumn{4}{|c|}{ Herbicida } \\
\cline { 2 - 5 } & $\mathrm{TC}^{1 /}$ & $\mathrm{HA}$ & $\mathrm{HB}$ & $\mathrm{HC}$ \\
\hline RB72454 & $100,00 \mathrm{aA}^{\frac{2}{-}}$ & $68,50 \mathrm{bB}$ & $60,56 \mathrm{cB}$ & $76,46 \mathrm{bB}$ \\
\hline RB835486 & $100,00 \mathrm{aA}$ & $71,11 \mathrm{bB}$ & $78,89 \mathrm{bB}$ & $75,11 \mathrm{bB}$ \\
\hline RB855113 & $100,00 \mathrm{aA}$ & $63,64 \mathrm{bB}$ & $93,19 \mathrm{aA}$ & $96,00 \mathrm{aA}$ \\
\hline RB855156 & $100,00 \mathrm{aA}$ & $88,27 \mathrm{aA}$ & $95,41 \mathrm{aA}$ & $91,29 \mathrm{aA}$ \\
\hline RB867515 & $100,00 \mathrm{aA}$ & $86,72 \mathrm{aB}$ & $76,75 \mathrm{bB}$ & $87,60 \mathrm{aB}$ \\
\hline RB925211 & $100,00 \mathrm{aA}$ & $87,16 \mathrm{aB}$ & $73,82 \mathrm{bB}$ & $98,21 \mathrm{aA}$ \\
\hline RB925345 & $100,00 \mathrm{aA}$ & $83,44 \mathrm{aB}$ & $100,00 \mathrm{aA}$ & $100,00 \mathrm{aA}$ \\
\hline RB937570 & $100,00 \mathrm{aA}$ & $88,01 \mathrm{aB}$ & $78,96 \mathrm{bB}$ & $95,96 \mathrm{aA}$ \\
\hline RB947520 & $100,00 \mathrm{aA}$ & $66,88 \mathrm{bB}$ & $79,00 \mathrm{bB}$ & $83,74 \mathrm{bB}$ \\
\hline SP80-1816 & $100,00 \mathrm{aA}$ & $86,19 \mathrm{aA}$ & $62,57 \mathrm{cB}$ & $91,93 \mathrm{aA}$ \\
\hline CV parcela (\%) & \multicolumn{5}{|c|}{11,21} \\
\hline CV subparcela (\%) & \multicolumn{5}{|c|}{12,17} \\
\hline
\end{tabular}

1/ TC: testemunha capinada; HA: ametryn $\left(2.000 \mathrm{~g} \mathrm{ha}^{-1}\right)$; HB: trifloxysulfuron-sodium $\left(22,5 \mathrm{~g} \mathrm{ha}^{-1}\right)$; $\mathrm{HC}$ : ametryn + trifloxysulfuron-sodium $\left(1.673+37,0 \mathrm{~g} \mathrm{ha}^{-1}\right) .{ }^{2 /}$ Médias seguidas de mesmas letras minúsculas, na coluna, e maiúsculas, na linha, constituem grupos homogêneos, conforme Scott-Knott $(\mathrm{p} \leq 0,05)$.

Tabela 10 - Altura de plantas (\%) de cana-de-açúcar, avaliada aos 360 dias após a aplicação dos herbicidas, em função de genótipos ou de aplicação de herbicidas isolados ou em mistura comercial

\begin{tabular}{|l|c|r|r|r|}
\hline \multirow{2}{*}{ Genótipo } & \multicolumn{4}{|c|}{ Herbicida } \\
\cline { 2 - 5 } & \multicolumn{1}{|c|}{$\mathrm{TC}^{1 /}$} & \multicolumn{1}{|c|}{ HA } & \multicolumn{1}{c|}{ HB } & \multicolumn{1}{c|}{ HC } \\
\hline RB72454 & $100,00 \mathrm{aA}^{\frac{2}{}}$ & $98,53 \mathrm{aA}$ & $82,54 \mathrm{bB}$ & $97,79 \mathrm{aA}$ \\
\hline RB835486 & $100,00 \mathrm{aA}$ & $89,34 \mathrm{bA}$ & $71,09 \mathrm{cB}$ & $95,27 \mathrm{aA}$ \\
\hline RB855113 & $100,00 \mathrm{aA}$ & $90,69 \mathrm{bB}$ & $88,38 \mathrm{aB}$ & $98,39 \mathrm{aA}$ \\
\hline RB855156 & $100,00 \mathrm{aA}$ & $90,38 \mathrm{bA}$ & $66,46 \mathrm{cB}$ & $98,46 \mathrm{aA}$ \\
\hline RB867515 & $100,00 \mathrm{aA}$ & $100,00 \mathrm{aA}$ & $90,65 \mathrm{aA}$ & $99,60 \mathrm{aA}$ \\
\hline RB925211 & $100,00 \mathrm{aA}$ & $88,16 \mathrm{bB}$ & $82,00 \mathrm{bB}$ & $94,19 \mathrm{aA}$ \\
\hline RB925345 & $100,00 \mathrm{aA}$ & $88,91 \mathrm{bA}$ & $96,88 \mathrm{aA}$ & $100,00 \mathrm{aA}$ \\
\hline RB937570 & $100,00 \mathrm{aA}$ & $82,34 \mathrm{bB}$ & $94,27 \mathrm{aA}$ & $92,34 \mathrm{aA}$ \\
\hline RB947520 & $100,00 \mathrm{aA}$ & $90,29 \mathrm{bA}$ & $98,18 \mathrm{aA}$ & $100,00 \mathrm{aA}$ \\
\hline SP80-1816 & $100,00 \mathrm{aA}$ & $94,13 \mathrm{aA}$ & $96,55 \mathrm{aA}$ & $98,09 \mathrm{aA}$ \\
\hline CV parcela (\%) & \multicolumn{5}{|c}{6,53} \\
\hline CV subparcela (\%) & \multicolumn{5}{|c}{7,64} \\
\hline
\end{tabular}

1/ TC: testemunha capinada; HA: ametryn $\left(2.000 \mathrm{~g} \mathrm{ha}^{-1}\right)$; HB: trifloxysulfuron-sodium $\left(22,5 \mathrm{~g} \mathrm{ha}^{-1}\right)$; $\mathrm{HC}$ : ametryn + trifloxysulfuron-sodium $\left(1.673+37,0 \mathrm{~g} \mathrm{ha}^{-1}\right) .{ }^{2 /}$ Médias com letras iguais minúsculas, na coluna, e maiúsculas, na linha, constituem grupos homogêneos, conforme Scott-Knott $(\mathrm{p} \leq 0,05)$.

ametryn + trifloxysulfuron-sodium, contrariamente ao denotado pelos autores para o genótipo RB867515, que foi menos intoxicado. Azania et al. (2005a, b), ao trabalharem com o genótipo RB835089 em campo, constataram que azafenidin + hexazinone e isoxaflutole prejudicaram o crescimento das plantas na avaliação realizada aos 180 DAT. Ressalta-se 
que as diferenças encontradas podem ser em função das características intrínsecas de cada cultivar, do tipo de solo, das condições climáticas e das características físico-químicas dos herbicidas testados e que isso leva à maior ou menor sensibilidade dos genótipos de cana-deaçúcar avaliados em várias regiões do Brasil, o que vem corroborar os resultados obtidos neste estudo de seletividade.

Os resultados da produtividade de colmos da cana-de-açúcar estão expostos na Tabela 11, na qual se observa que os genótipos RB867515, RB925345, RB937570, RB947520 e SP80-1816 foram os mais produtivos e também não diferiram da testemunha. O genótipo RB855156 apresentou menor produtividade de colmos quando utilizado ametryn, trifloxysulfuronsodium ou a mistura de ametryn + trifloxysulfuron-sodium; por outro lado, os genótipos RB72454 e RB835486 demonstraram maior produtividade de colmos quando se aplicaram os herbicidas ametryn e a mistura formulada, porém com resposta intermediária para o trifloxysulfuron-sodium.

Existem vários trabalhos que enfatizam as diferenças entre herbicidas aplicados sobre alguns genótipos de cana-de-açúcar (Velini et al., 2000; Negrisoli et al., 2004; Barela \& Christoffoleti, 2006). Foram detectadas diferenças significativas entre genótipos sob

Tabela 11 - Produtividade de cana-de-açúcar (\%), em função de genótipos tratados com herbicidas isolados e em mistura comercial

\begin{tabular}{|l|c|r|r|r|}
\hline \multirow{2}{*}{ Genótipo } & \multicolumn{4}{|c|}{ Herbicida } \\
\cline { 2 - 5 } & \multicolumn{1}{|c|}{$\mathrm{TC}^{\underline{1}}$} & \multicolumn{1}{|c|}{$\mathrm{HA}$} & \multicolumn{1}{c|}{$\mathrm{HB}$} & $\mathrm{HC}$ \\
\hline RB72454 & $100,00 \mathrm{aA}^{\frac{2}{}}$ & $95,92 \mathrm{aA}$ & $90,86 \mathrm{bB}$ & $100,00 \mathrm{aA}$ \\
\hline RB835486 & $100,00 \mathrm{aA}$ & $100,00 \mathrm{aA}$ & $83,10 \mathrm{cB}$ & $99,82 \mathrm{aA}$ \\
\hline RB855113 & $100,00 \mathrm{aA}$ & $98,84 \mathrm{aA}$ & $95,34 \mathrm{aA}$ & $86,53 \mathrm{bB}$ \\
\hline RB855156 & $100,00 \mathrm{aA}$ & $92,24 \mathrm{aB}$ & $81,69 \mathrm{cC}$ & $90,69 \mathrm{bB}$ \\
\hline RB867515 & $100,00 \mathrm{aA}$ & $96,30 \mathrm{aA}$ & $100,00 \mathrm{aA}$ & $99,11 \mathrm{bA}$ \\
\hline RB925211 & $100,00 \mathrm{aA}$ & $100,00 \mathrm{aA}$ & $99,32 \mathrm{aA}$ & $90,36 \mathrm{bB}$ \\
\hline RB925345 & $100,00 \mathrm{aA}$ & $98,51 \mathrm{aA}$ & $95,93 \mathrm{aA}$ & $100,00 \mathrm{aA}$ \\
\hline RB937570 & $100,00 \mathrm{aA}$ & $96,38 \mathrm{aA}$ & $99,31 \mathrm{aA}$ & $100,00 \mathrm{aA}$ \\
\hline RB947520 & $100,00 \mathrm{aA}$ & $99,46 \mathrm{aA}$ & $100,00 \mathrm{aA}$ & $100,00 \mathrm{aA}$ \\
\hline SP80-1816 & $100,00 \mathrm{aA}$ & $100,00 \mathrm{aA}$ & $100,00 \mathrm{aA}$ & $100,00 \mathrm{aA}$ \\
\hline CV parcela (\%) & \multicolumn{5}{|c}{3,10} \\
\hline CV subparcela (\%) & \multicolumn{5}{|c}{4,69} \\
\hline
\end{tabular}

1/ TC: testemunha capinada; HA: ametryn $\left(2.000 \mathrm{~g} \mathrm{ha}^{-1}\right)$; HB: trifloxysulfuron-sodium $\left(22,5 \mathrm{~g} \mathrm{ha}^{-1}\right)$; $\mathrm{HC}$ : ametryn + trifloxysulfuron-sodium $\left(1.673+37,0 \mathrm{~g} \mathrm{ha}^{-1}\right)$. ${ }^{2 /}$ Médias com letras iguais minúsculas, na coluna, e maiúsculas, na linha, constituem grupos homogêneos, conforme Scott-Knott $(\mathrm{p} \leq 0,05)$. efeito de herbicidas na produtividade de colmos (Montório et al., 2008; Freitas et al., 2004; Azania et al., 2005a, b), confirmando o que foi observado neste trabalho ao analisar dez genótipos de cana-de-açúcar e três herbicidas.

Os genótipos RB925345 e RB947520 foram mais tolerantes a todos os herbicidas e não diferiram da testemunha, apresentando superioridade com relação aos demais. Contrariamente, foi observado que o genótipo RB835486, para a maioria das variáveis avaliadas, apresentou-se como o menos tolerante na presença dos herbicidas ametryn, trifloxysulfuronsodium e ametryn + trifloxysulfuron-sodium.

Diante dos resultados obtidos, conclui-se que a seletividade do ametryn, trifloxysulfuronsodium e da mistura formulada comercialmente ametryn + trifloxysulfuron-sodium foi dependente do genótipo de cana-de-açúcar e da variável em estudo. Os genótipos RB867515, RB925345, RB947520 e SP80-1816 destacaram-se, apresentando maior produtividade de colmos, sendo os mais tolerantes a esses herbicidas. Além desses genótipos, o RB925345, recentemente lançado comercialmente, e o RB947520, em fase de estudo pelo programa de melhoramento da Rede Interuniversitária para Desenvolvimento do Setor Sucroalcooleiro (RIDESA), também demonstraram tolerância aos herbicidas avaliados, com produtividade de colmo semelhante à da testemunha sem herbicida.

\section{AGRADECIMENTOS}

Ao Conselho Nacional de Desenvolvimento Científico e Tecnológico (CNPq-Brasil), pela concessão de bolsas.

\section{LITERATURA CITADA}

AZANIA, C. A. M. et al. Seletividade de imazapic às soqueiras de cana-de-açúcar (Saccharum spp.). Planta Daninha, v. 19, n. 3, p. 345-350, 2001.

AZANIA, C. A. M. et al. Seletividade de herbicidas. IUtilização do método de testemunhas pareadas em experimento com cana-de-açúcar. Planta Daninha, v. 23, n. 4, p. 661-667, 2005a.

AZANIA, C. A. M. et al. Seletividade de herbicidas. II Aplicação de herbicidas em pós-emergência inicial e tardia da cana-de-açúcar na época das chuvas. Planta Daninha, v. 23, n. 4, p. $669-675,2005$ b.

Planta Daninha, Viçosa-MG, v. 28, n. 2, p. 329-338, 2010 
AZANIA, C. A. M. et al. Seletividade de herbicidas. III Aplicação de herbicidas em pós-emergência inicial e tardia da cana-de-açúcar na época da estiagem. Planta Daninha, v. 23, n. 3, p. 489-495, 2006.

BARELA, J. F.; CHRISTOFFOLETI, P. J. Seletividade de herbicidas aplicados em pré-emergência da cultura da cana-deaçúcar (RB867515) tratada com nematicidas

Planta Daninha, v. 24, n. 2, p. 371-378, 2006.

COMISSÃO DE FERTILIDADE DO SOLO DO ESTADO DE MINAS GERAIS - CFSEMG. Recomendações para o uso de corretivos e fertilizantes em Minas Gerais - 5a aproximação. Viçosa, MG: Universidade Federal de Viçosa, 1999. $359 \mathrm{p}$.

CHRISTOFFOLETI, P. J. et al. Carfentrazone-ethyl aplicado em pós-emergência para o controle de Ipomoea spp. e Commelina benghalensis na cultura da cana-de-açúcar. Planta Daninha, v. 24, n. 1, p. 83-90, 2006.

CHRISTOFFOLETI, P. J. et al. Manejo de plantas daninhas na cultura da cana-de-açúcar: novas moléculas herbicidas. Disponível em: <http://www.potafos.org > Acesso em: 19 set. 2008

DAS, A. C.; DEBNATH, A.; MUKHERJEE, D. Effect of the herbicides oxadiazon and oxyfluorfen on phosphates solubilizing microorganisms and their persistence in rice fields. Chemosphere, v. 53, n. 5, p. 217-221, 2003.

EMPRESA BRASILEIRA DE PESQUISA AGROPECUÁRIA - EMBRAPA. Centro Nacional de Pesquisa Agropecuária de Solos. Sistema brasileiro de classificação de solos. Rio de Janeiro: 2006. 412 p.

FENG, P. C. C. et al. Glyphosate inhibits rust diseases in glyphosate-resistant wheat and soybean. Proc. Nat. Acad. Sci., v. 102, n. 48, p. 17290-17295, 2005.

FERREIRA, E. A. et al. Sensibilidade de cultivares de canade-açúcar à mistura trifloxysulfuron-sodium + ametryn.

Planta Daninha, v. 23, n. 1, p. 93-99, 2005.

FREITAS, S. P. et al. Controle químico de Rottboellia exaltata em cana-de-açúcar. Planta Daninha, v. 22, n. 3, p. 461-466, 2004.

INMAN-BAMBER, N. G. Temperature and seasonal effects on canopy development and light interception of sugarcane. Field Crops Res., v. 36, n. 1, p. 41-51, 1994.

KUVA, M. A. et al. Períodos de interferência das plantas daninhas na cultura da cana-de-açúcar. III - Capim-brachiaria (Brachiaria decumbens) e capim-colonião (Panicum maximum). Planta Daninha, v. 21, n. 1, p. 37-44, 2003

KUVA, M. A. et al. Padrões de infestação de comunidades de plantas daninhas no agroecossistema de cana-crua.

Planta Daninha, v. 26, n. 3, p. 549-557, 2008.
MONTÓRIO, G. A. et al. Seletividade de herbicidas sobre as características de produção de cana-de-açúcar utilizando-se suas testemunhas. Disponível em: <http:// www.upf.br/rbherbicidas/download/RBH226> Acesso em: 21 out. 2008

NEGRISOLI, E. et al. Seletividade de herbicidas aplicados em pré-emergência na cultura da cana-de-açúcar tratada com nematicidas. Planta Daninha, v. 22, n. 4, p. 567-575, 2004

OLIVEIRA Jr. et al. Trifloxysulfuron-sodium: nova opção para o controle seletivo de plantas daninhas na cultura do algodão. R. Oleag. Fibrosas, v. 5, n. 2, p. 345-354, 2001.

PROCÓPIO, S. O.; SILVA, A. A.; VARGAS, L. Manejo e controle de plantas daninhas em cana-de-açúcar. In: VARGAS, L.; ROMAN, E. S. (Eds.). Manual de manejo e controle de plantas daninhas. Bento Gonçalves: Embrapa Uva e Vinho, 2004. p. $397-452$.

RAWLS, E. K. et al. Envoke: a new herbicide for weed control in U.S. sugarcane. J. Am. Soc. Sugarcane Technol., v. 23, n. 1, p. 96,2003

RIZZARDI, M. A. et al. Ação de herbicidas sobre mecanismos de defesa das plantas aos patógenos. Ci. Rural, v. 33, n. 5 , p. $957-965,2003$

REIS, M. R. et al. Dinâmica de nutrientes em tecidos foliares de cana-de-açúcar após aplicação de herbicidas. Planta Daninha, v. 26, n. 1, p. 175-184, 2008.

RODRIGUES, B. N.; ALMEIDA, F. R. Guia de herbicidas 5.ed. Londrina: Edição dos Autores, 2005. 591 p.

SCOTT, A.; KNOTT, M. Cluster-analysis method for grouping means in analysis of variance. Biometrics, v. 30, n. 3, p. 507-512, 1974.

SISTEMA DE AGROTÓXICOS FITOSSANITÁRIOS AGROFIT. Disponível em: <http://extranet.agricultura.gov.br/ agrofit>. Acesso em: 19 de set. de 2008

TUFFI SANTOS, L. D. et al. Glyphosate sobre a resistência à ferrugem (Puccinia psidii) do eucalipto. Planta Daninha, v. 25, n. 1, p. $139-147,2007$.

VELINI, E. D. et al. Avaliação dos efeitos de doses do herbicida clomazone, aplicado em pós-emergência inicial, sobre o crescimento e produtividade de soqueira de cana-deaçúcar (Saccharum officinarum cv. SP71-1406). STAB, v. 12, n. 2 , p. $30-35,1993$

VELINI, E. D. et al. Avaliação da seletividade da mistura de oxyfluorfen e ametryne, aplicada em pré e pós-emergência, a dez variedades de cana-de-açúcar (cana planta). Planta Daninha, v. 18, n. 2, p. 123-134, 2000

VICTÓRIA FILHO, R.; CAMARGO, P. N. Efeitos de herbicidas nos teores de macronutrientes e nas características tecnológicas da cana-de-açúcar (Saccharum spp.). I Misturas de herbicidas em pós-emergência. Planta Daninha, v. 3, n. 2, p. 96-107, 1980. 